\title{
Dislocation of the ulnar nerve at the elbow in an elite wrestler
}

\author{
Szabolcs Lajos Molnar, ${ }^{1}$ Peter Lang, ${ }^{2}$ János Skapinyecz, ${ }^{3}$ Babak Shadgan ${ }^{4,5}$ \\ ${ }^{1}$ Department of Orthopaedic Surgery, Mutua Navarra, Pamplona, Spain; \\ 2Department of Orthopaedics, Hospitaller Brothers of Saint John of God, Budapest, Hungary; \\ ${ }^{3}$ Department of Neurosurgery, Teaching Hospital of B-A-Z County, Miskolc, Hungary; \\ ${ }^{4}$ Medical Committee, International Federation of Associated Wrestling Styles (FILA), Vancouver, Canada; \\ ${ }^{5}$ Department of Orthopaedic Surgery, University of British Columbia, Vancouver, Canada
}

Correspondence to Dr Szabolcs Lajos Molnar, szabolcsmolnardr@gmail.com

\section{Summary}

Dislocation of the ulnar nerve is uncommon among the general population, but it has been reported more frequently in athletes who use their upper limbs to make forceful and resisted flexion of elbow joint. The authors report a unique case of ulnar nerve dislocation in an elite wrestler treated by partial epicondylectomy and subcutaneous transposition of the ulnar nerve. Following the surgery, a supervised and well-designed sport-specific rehabilitation program is a necessary requirement for a rapid return to sport. Such a program requires a bilateral consultation and collaboration between treating physician and trainer of the wrestler. The athlete regained his full function and returned to wrestling after a 3-month sport-specific functional rehabilitation program.

\section{BACKGROUND}

While dislocation of the ulnar nerve is uncommon among the general population, it has been reported more frequently in athletes who use their upper limbs to make forceful and resisted flexion of elbow joint. ${ }^{1-3}$ We report a case of ulnar dislocation in an elite wrestler, emphasising on the importance of the sport-specific rehabilitation program assisted by the trainer of the athlete following surgical intervention.

\section{CASE PRESENTATION}

A 17-year-old elite wrestler suffered an injury after a simple fall on the elbow during a wrestling training session, in spite of the fact that he was well prepared and fit. He had sharp, electric-type pain around the medial epicondyle of his left elbow with elbow-flexion during wrestling 1 week after the trauma.

\section{INVESTIGATIONS}

Physical examination including provocative tests confirmed flexion-induced ulnar nerve dislocation. No remarkable swelling or ulnar motor deficit was observed in the nerve conduction studies and elbow movement during daily life was pain-free. Imaging investigation including dynamic sonography of the elbow confirmed dynamic instability of the ulnar nerve and showed that there was no dysplasia of the retrocondylar ulnar groove and also ruled out snapping triceps syndrome.

\section{DIFFERENTIAL DIAGNOSIS}

As ulnar nerve hypermobility has been reported in 2-47\% of asymptomatic individuals, accurate diagnosis of the ulnar nerve dislocation requires a careful history taking, a thorough physical examination (with standardised clinical evaluation technique) followed by appropriate anatomical and functional imaging investigation such as dynamic sonography of the elbow. ${ }^{3-5}$

Care should be taken to make a good differential diagnosis from snapping triceps syndrome (sonography), arcade of Struther (x-ray), oedema of the ulnar nerve due to contusion (sonography), dysplasia of the retrocondylar ulnar groove (sonography) or entrapment in the origin of the two heads of the flexor carpi ulnar muscle (nerve conduction studies). ${ }^{3} 6$

\section{TREATMENT}

Considering the professional level of the athlete that warranted a definite treatment with a rapid return to sport, a surgical intervention including partial epicondylectomy followed by subcutaneous transposition and fixation of the ulnar nerve, a modified procedure described originally by King and Morgan ${ }^{7}$ was performed (figure 1).

\section{OUTCOME AND FOLLOW-UP}

Following the surgery, a functional sport-specific rehabilitation program was promptly undertaken. After removing the sutures, patient was instructed to start running, cycling, swimming (free style) and reinforcement of the other three extremities and the trunk. Following a gradual improvement in muscle function, he began to exercise his operated arm with light weights after the fourth week of surgery. He was allowed from the sixth week to increase the intensity and complexity of arm movements such as rope climbing that progressed to throwing manoeuvres in the mat on the eighth week. He started light wrestling exercises, approximately at $30-50 \%$ of maximum intensity with an opponent in a lower weight category from the tenth week. He regained his full activity and fitness at the end of the twelfth week after the surgery. The wrestler was carefully observed and assisted by his trainer and 


\section{BMJ Case Reports}

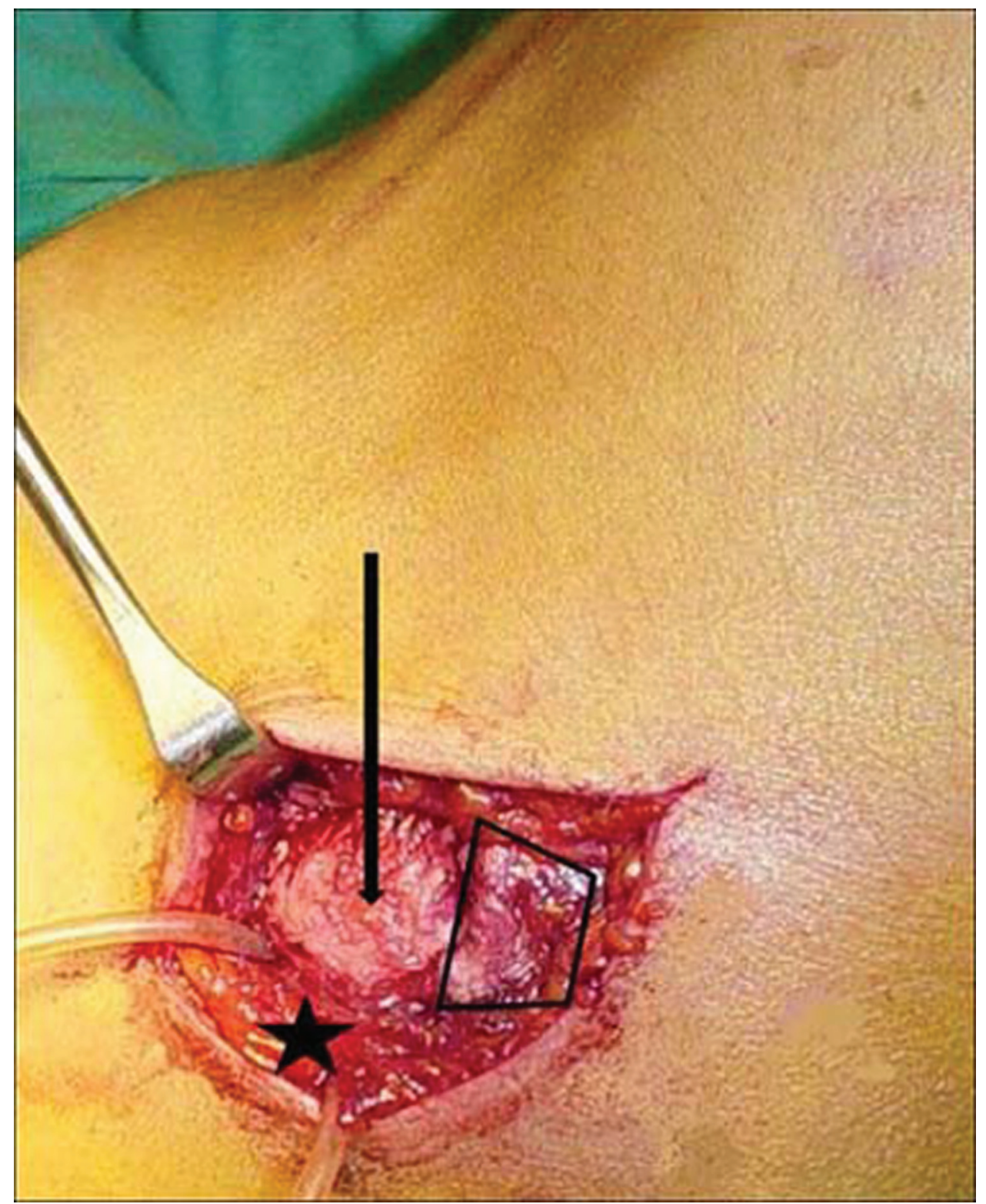

Figure 1 Isolation of the ulnar nerve and partial epicondylectomy (left elbow, ulnar side - intraoperative picture). *: ulnar nerve (isolated with rubber), arrow: resected epocondyle, trapezoid area: the theoretical ligamentum epicondyloolecranicum.

regularly visited and assessed by the surgeon during all rehabilitation sessions.

\section{DISCUSSION}

Ulnar nerve dislocation was first described by Blattmann in $1851 .{ }^{9}$ This condition is described in the medical literature with different terms including luxation, instability, hypermobility and recurrent luxation / subluxation of the ulnar nerve. ${ }^{34}$ 9-10 Each of them has its own origin, explanation and emphasises a different clinical aspect of the cubital tunnel syndrome. This is a rare nerve entrapment syndrome, which is caused by the absence, rupture or laxity of the epicondyloolecranial ligament. Dysplasia of the retrocondylar ulnar groove also increases the likelihood of the condition. ${ }^{3}$ By flexing the elbow, the nerve leaves its sulcus and becomes compressed by the medial humeral epicondyle. In athletes with well-developed upper limb muscles, the prominent medial head of triceps further pushed out the nerve from the sulcus when flex the elbow. It might be a reason for rapid development of this pathology in athletes.

Normal activity is rarely affected by ulnar nerve dislocation within a general lifestyle; hence, several years can pass from the beginning of the symptoms until the evolution of the late ulnar paresis. ${ }^{10}$ However, in athletes who require frequent forceful flexion of elbow, especially in those with strong and developed upper limb muscles, ulnar nerve dislocation results in inconvenient symptomatic condition that impedes the competitors and therefore needs early surgical attention. ${ }^{4} 68$ Due to the diversity and complexity of the possible causes in a relatively small anatomic region, there is no consensus in the literature about the ideal surgical treatment, but there is a trend for partial epicondylectomy and subcutaneous transposition in case of dislocation. ${ }^{4} 6$

Following the surgery, a supervised and well-designed sport-specific rehabilitation program is a necessary require- 
ment for a rapid return to sport. Such a program requires a bilateral consultation and collaboration between treating physician and trainer of the wrestler. The athlete regained his full function and returned to wrestling after a 3-month sport-specific functional rehabilitation program.

\section{Learning points}

- Dislocation of the ulnar nerve is uncommon among the general population, but it has been reported more frequently in athletes who use their upper limbs to make forceful and resisted flexion of elbow joint.

- We report a unique case of ulnar nerve dislocation in an elite wrestler treated by partial epicondylectomy and subcutaneous transposition of the ulnar nerve.

- Due to the diversity and complexity of the possible causes in a relatively small anatomic region, there is no consensus in the literature about the ideal surgical treatment, but there is a trend for partial epicondylectomy and subcutaneous transposition in case of dislocation.

- We would like to emphasise on the importance of the sport-specific rehabilitation program assisted by the trainer of the athlete following surgical intervention.

- The athlete regained his full function and returned to wrestling after a 3-month sport-specific functional rehabilitation program.
Acknowledgements The authors would like to express their honour to Miklós Farkasházi (Consultant Orthopaedic Surgeon) and Andras Sike (Olympic Champion, 1988, $57 \mathrm{~kg}$ Greco, Seoul), the coach of the wrestler (FTC Budapest, Hungary and the Hungarian Junior Greco Team) in the contribution of the sport-specific rehabilitation programe.

Competing interests None.

Patient consent Obtained.

\section{REFERENCES}

1. Capasso G, Testa V, Cappabianca S, et al. Recurrent dislocation of the ulnar nerve in athletes: a report of two cases. Clin J Sport Med 1998;8:56-8.

2. Kamano M, Koshimune M, Kazuki K. Bilateral recurrent dislocation of the ulnar nerve in semiprofessional swimmer: a case report. Clin J Sport Med 2005; 15:191.

3. Xarchas KC, Psillakis I, Koukou 0, et al. Ulnar nerve dislocation at the elbow: review of the literature and report of three cases. Open Orthop J 2007;1:1-3.

4. Calfee RP, Manske PR, Gelberman RH, et al. Clinical assessment of the ulnar nerve at the elbow: reliability of instability testing and the association of hypermobility with clinical symptoms. J Bone Joint Surg Am 2010;92:2801-8.

5. Jacobson JA, Jebson PJ, Jeffers AW, et al. Ulnar nerve dislocation and snapping triceps syndrome: diagnosis with dynamic sonography-report of three cases. Radiology 2001;220:601-5.

6. Schnabl SM, Kisslinger F, Schramm A, et al. Objective outcome of partial medial epicondylectomy in cubital tunnel syndrome. Arch Orthop Trauma Surg 2010;130:1549-56.

7. Kaempffe FA, Farbach J. A modified surgical procedure for cubital tunnel syndrome: partial medial epicondylectomy. J Hand Surg Am 1998;23:492-9.

8. King T, Morgan FP. Late results of removing the medial humeral epicondyle for traumatic ulnar neuritis. J Bone Joint Surg Br 1959;41-B:51-5.

9. Blattmann A. Beobachtung einer Dislokation des N. ulnaris. Dtsch Klin 1851:435-7.

10. Childress HM. Recurrent ulnar-nerve dislocation at the elbow. Clin Orthop Relat Res 1975:168-73.

This pdf has been created automatically from the final edited text and images.

Copyright 2011 BMJ Publishing Group. All rights reserved. For permission to reuse any of this content visit http://group.bmj.com/group/rights-licensing/permissions.

BMJ Case Report Fellows may re-use this article for personal use and teaching without any further permission.

Please cite this article as follows (you will need to access the article online to obtain the date of publication).

Molnar SL, Lang P, Skapinyecz J, Shadgan B. Dislocation of the ulnar nerve at the elbow in an elite wrestler. BMJ Case Reports 2011;

10.1136/bcr.02.2011.3806, date of publication

Become a Fellow of BMJ Case Reports today and you can:

- Submit as many cases as you like

- Enjoy fast sympathetic peer review and rapid publication of accepted articles

- Access all the published articles

- Re-use any of the published material for personal use and teaching without further permission

For information on Institutional Fellowships contact consortiasales@bmjgroup.com

Visit casereports.bmj.com for more articles like this and to become a Fellow 